\title{
A Qualitative Meta-synthesis of Research on Dynamic Assessment of Second/Foreign Language Learning: Implications for Language Teachers
}

\author{
Mahsa Ghanbarpour \\ University of Tehran, Iran
}

\begin{abstract}
Striving to integrate teaching and assessment, Dynamic Assessment (DA) is a pivotal classroom teacher assessment practice at teachers' disposal. Although a multitude of research has delved into different aspects of DA of second/foreign language learning, whether their findings find their way into educational practice is a cause for concern. Adopting a meta-synthesis methodology, this study served a two-fold purpose: (a) to distill the pedagogical conclusions on the effectiveness of $\mathrm{DA}$, and (b) to develop a more informed understanding of a set of guidelines for the implementation of DA so that the practical implications of research findings for teacher educators and teachers be better grasped.
\end{abstract}

Index Terms-qualitative research, second language instruction, second language learning, sociocultural patterns, alternative assessment, dynamic assessment

\section{INTRODUCTION}

Quantitative research methods and those employing experimental conditions or large data sets can, doubtless, lead to invaluable findings important to policymakers in the realm of education. Having said that, qualitative research synthesis and systematic reviews of primary research on education in general and meta-synthesis in particular might better unveil the practical implications of empirical research findings for teachers and provide them with instructional guidelines that would enhance teaching practices and/or learning outcomes. As far as second language acquisition (henceforth SLA) is concerned, meta-syntheses "may provide a different set of instructional strategy recommendations for English language teachers working in a wide variety of settings" (Tellez \& Waxman, 2006, p. 250), which could, at least partly, justify why "qualitative studies in second language teaching are increasing in both number and quality" (ibid, p. 246) and the number of researchers and organizations, such as Campbell Collaboration, trying to synthesize primary research findings is escalating.

Although the effectiveness of mediation in promoting learner development and the benefits of DA implementation in classroom assessment are bandied about in the related literature, (see the research reports marked with an asterisk in the reference list), research-based qualitative accounts that provide teacher educators and language teachers with practical guidelines on the effective implementation of DA are quite scanty. To fill this void, this meta-synthesis sought to amass information about the conclusions that have been pointed to in research studies on the effectiveness and applicability of second language (L2) DA and to identify a set of clear guidelines on the implementation of DA in classroom context.

\section{LITERATURE REVIEW}

Dynamic assessment "challenges conventional views on teaching and assessment by arguing that these should not be seen as separate activities but should instead be fully integrated" (Poehner, 2008, p. 5). "Within this framework, efforts to understand, or assess, learner abilities necessarily involve promoting their development through instructional intervention. Put another way, the object of assessment is fully understood by actively seeking to change it" (Poehner, 2011a, p. 100). As far as classroom assessment is concerned, DA helps teachers track the ongoing process of learning and make conscious decisions, informed by the results of previous assessment, as to how subsequent instruction should be organized. A sizeable portion of primary research into English as a Foreign Language (EFL), English as a Second Language (ESL), and SLA has looked at different aspects of DA and its effectiveness to unite instruction and assessment in the social environment of language classroom (see the studies marked with an asterisk in the reference list). For instance, previous studies scrutinized the applicability of DA to the development of learners' (a) word recognition and reading comprehension (Carney \& Cioffi, 1990; Dorfler, Golke, \& Artelt, 2009), (b) writing skills (Nassaji \& Swain, 2000; Shrestha \& Coffin, 2012), (c) listening comprehension (Ableeva \& Lantolf, 2011), and (d) speaking skills (Hill \& Sabet, 2009); however, more needs to be done by way of research to render empirical findings applicable to classroom assessment. 
As far as the purpose of the study is concerned, as noted in Rezaee and Ghanbarpour (2016), classroom assessment, also referred to as 'ZPD-based assessment' and 'classroom teacher assessment' (see Rea-Dickins, 2004; van Compernolle \& Kinginger, 2013), is regarded as an alternative to standardized testing (Hill \& Sabet, 2009, p. 537) in in classroom context. Although DA, as a form of classroom assessment, is found to be feasible and effective "not only in the field of cognitive performance but also in such curricular domains as EFL learning" (Kozulin \& Grab, 2002, p. 122), whether or not enough heed is paid to the findings of ongoing research on DA in the field of Second Language Teacher Education (SLTE) can be the subject of some lively debate. To exemplify, preservice and in-service teacher-training course (TTC) organizers may make no mention of the progress made in the field in the course curricula; research findings might have no manifestation in such courses, accordingly, and they may simply remain as unwarranted, ancillary suggestions and theories on paper. Teacher trainees and language teachers, hence, would be liable to make no use of the developments in the field to advance on their way to professional excellence. Also, depriving learners of the benefits of recent research findings, such inadvertent negligence has some repercussions for students as well.

Lack of familiarity and knowledge with/about principles of DA among teacher trainers/educators, language teachers, and those who are involved in teachers' professional development is, doubtless, a barrier to DA finding its way into educational practice. It is high time we pondered over a simple question: when the cornerstone of micro validity (see Poehner, 2011b) and the overall success of DA lie with the teacher's/mediator's ability in providing learners with negotiated mediation attuned to their emerging needs, how can teachers who are deprived of a basic understanding of DA remain proactive in conducting classroom assessment?

Mediating sources, both external (e.g., policy makers) and internal (e.g., teachers and teacher educators) (see Tierney, 2006), can make way for practicable change in the prevailing position of assessment in general and DA in particular by taking on an intermediary role to bridge the gap between language research and language pedagogy (see Ellis, 2010, 2013; Gass, 1995; Ishihara, 2010; Nuland, 2011; Nunan, 1991). Given that DA is no more a newfangled framework in the realm of education, the present study is an attempt to provide a set of guidelines to help teacher trainers and teachers get a better understanding of DA principles, its practicality and benefits, so that, hopefully, in the future, DA becomes a household approach in many educational settings.

In an attempt to settle the aforementioned issues, the present study will look at conclusions and suggested guidelines in studies where DA was used to promote language development, inform intervention, or break new ground for conceiving of classroom assessment. It is an attempt to (a) sensitize classroom practitioners to the importance of being familiar with the dynamic traits of learner development, (b) avail language teachers of guidelines on providing learners with meditational means of development by attending to empirical research findings, and (c) give them some hints, extracted from relevant primary research, to help them engage in organizing complimentary classroom-based L2 DA practices that can foster learner development. Striving to take a step to permit classroom DA to achieves its pedagogical potential and provide a set of guidelines for teacher trainers and language teachers on implementing DA in classroom, the present study addresses two main research questions: 1) What pedagogical and theoretical conclusions have been discussed in the existing primary research on the usefulness of DA? 2) What common guidelines can be derived from studies on DA to assist language teachers to implement DA practices?

\section{METHOD}

\section{A. Design}

To provide language teachers and teacher educators with empirical evidence, findings, assertions, and guidelines put forward in primary research regarding the usefulness and practicality of DA for language teaching/learning, the present meta-synthesis was carried out. Meta-synthesis was employed because, as stated earlier, it aims at (a) identifying ubiquitous phenomena and common themes observed or emerged in and from a selection of primary studies, (b) presenting key implications realized from research findings, and (c) identifying, comparing, combining, summarizing, analyzing, and interpreting the data and supported findings from across studies in terms of their quality and utility (Major \& Savin-Baden, 2010; Thorne et al., 2004, Zhao, 1991) and was found to be suitable for fulfilling the dual purpose of the present work. Sandelowski, Docherty, and Emden (1997) delineated three general strategies for synthesizing qualitative studies: (a) integrating the findings of one prominent researchers' work over time, (b) integrating the results of research across both researchers and time, and (c) transforming qualitative data into counts and analyzing them quantitatively. It is worth noting that the present meta-synthesis adopted the second aforementioned strategy.

To interpret the data and distill evidence, the criteria Norris and Ortega (2007) established for meta-synthesis was used, according to which any systematic research review should possess three characteristics. First, the criteria for selection, inclusion, and exclusion of the studies should be explicitly denoted and rationalized. Second, instead of summarizing individual research reports and paying attention to what researchers claim their findings mean, which is quite commonplace in traditional reviews, critical and intense scrutiny is to be given to the evidence displayed in each study, and "numerical, visual, and textual displays of aggregated and reanalyzed primary data across studies" (Norris \& Ortega, 2007, p. 808) should be presented. Third, to integrate individual research evidence into a whole which is greater than the sum of the parts, a coding book, determining what to look for in the studies, should be used. Such coding 
categories are usually clarified in tables or appendices. With regard to the third criterion, the coding of the present metasynthesis was done inductively and the axioms and posteriori themes emerged in the process of reviewing the data.

\section{B. Data Collection}

\section{Search Terms and Procedures}

The articles included in this meta-synthesis were gathered in July 2014. Given that study sampling is typically purposive and selective in qualitative meta-synthesis (Norris \& Ortega, 2007; Suri \& Clarke, 2009), the initial literature was purposefully searched for by retrieving related articles from databases such as Academic Search Complete, Education Resources Information Center (ERIC), JSTOR, Modern Language Association (MLA), ProQuest, PsycINFO, Springer, Social Science Citation Index, and Web of Science.

The search terms 'dynamic assessment (DA)', 'sociocultural theory (SCT)', 'activity theory', 'zone of proximal development (ZPD)', 'ZPD-based assessment', 'mediated learning experience (MLE)', 'scaffolding', 'classroom assessment', 'classroom teacher assessment', 'Vygotsky', as well as their wild cards were employed to locate and retrieve potential research reports for this meta-synthesis. Author searches were also conducted with the names of eminent researchers who were publishing in the field of DA (e.g., Lantolf, Poehner, van Compernolle, etc.). Also, Journal of Cognitive Education and Psychology, which accords special attention to DA, was searched. The initial search yielded a total 82 research studies published from 1987 to 2014.

\section{Quality Considerations: Inclusion Criteria}

An important issue in the selection of data to be used for meta-synthesis is that the criteria for both the inclusion and exclusion of primary research studies should be clearly expounded on (Welch, 2008). To enhance the quality of the studies used in this meta-synthesis, the number of collected potential articles was lowered by applying a predetermined criterion: the inclusion of published peer-reviewed quantitative, qualitative, theoretical, and case studies. Hence, dissertations, book reviews, and conference presentations were all left out.

Having in mind the focus of the research questions and contemplating the need to merge comparable results and data types, the researcher eliminated those peer-reviewed studies that despite concentrating on DA, did not match the purpose of this meta-synthesis, that is, examining the empirical findings and practical implications of DA for language teachers and teacher educators as well as applications of DA procedures to L2 classroom assessment and pedagogy. Also, those studies that looked at Computerized Dynamic Assessment (C-DA) (e.g., Poehner \& Lantolf, 2013) were excluded.

Finally, to improve the trustworthiness of the study, the collected data set was narrowed down once more by deciding on a time frame for inclusion, and only those studies which were published between 1990 and 2014, a time period when DA found its way into the practice of educational mainstream and original research attended to its principles in pedagogy, were included in the final data set.

\section{The Final Data Set}

The selected articles were then reviewed by the researcher and a Ph.D. candidate of Teaching English as a Foreign Language (TEFL) whose doctoral dissertation was on DA to make sure that the selected studies would closely align with the rationale and purpose of this investigation. After evaluating all of the retrieved literature on the basis of the aforementioned data selection procedure, 41 peer-reviewed studies were retained as the body of research for the present meta-synthesis. These studies are identified with asterisk in the reference list.

\section{Data Analysis}

Analysis for this meta-synthesis followed the six-phased interpretive approach as delineated by Suri and Clarke (2009), according to which after the first three phases, that is, drawing from relevant philosophical and theoretical discussions, identifying an appropriate purpose, and searching for pertinent evidence, in phase four, the collected evidence must be distilled and interpreted. This phase is described in the subsequent section below (i.e., the results). Next, in the fifth phase, connected understandings must be developed by identifying the common patterns, features, and guidelines across the studies, which is presented in the 'results' section of the present work. The last phase is "communication with the audience" (Suri \& Clarke, 2009, p. 414), which is presented under the title of 'discussion and conclusions'. Since in the conclusion section, meta-synthesis is expected to communicate with the target audience (see Noblit \& Hare, 1988) and given that simply summarizing findings of individual studies is to be avoided, the excerpts presenting mediated interactions in primary research were pondered over so as to pull out relevant information on the potential of DA for L2 classroom context prior to devising the main themes and guidelines.

\section{Coding the Data}

Each paper came under careful scrutiny by two readers (i.e., the researcher and a Ph.D. candidate of TEFL working on DA) separately and independently; detailed notes were taken on the key themes, phrases, concepts, metaphors, and substantive categories of study features, and an initial template was made. In fact, Noblit and Hare (1988) used the term metaphor to refer to themes, perspectives, organizers, and/or concepts revealed by qualitative studies. Put another way, "a metaphor works to portray or explain difference when differences are represented as familiar entities within an equally familiar metaphorical explanation" (Thorne et al., 2004, p. 1355). The two readers, then, discussed the 
identified methodological features of the data to find the discrepancies and conclude an agreement in terms of the distilled evidence of the potential of DA for L2 learning contexts and guidelines for its implementation.

After making the necessary amendments to the initial template, certain features of the data (i.e., the selected primary research), including approaches taken to DA, methodological features, sample and participant features, sampling technique, type and duration of instructional mediation/interventions, Learning contexts (i.e., second/foreign language learning), dependent and independent variables, available findings for qualitative meta-synthesis, and techniques for measuring outcomes, were coded prior to deciding what relevant conclusions/guidelines to include and how to do so. The simple agreement ratio (see Orwin, 1994) between the two coders was 0.88 for the final coding and classification.

\section{RESULTS}

\section{A. Emergent Themes: Practical Implementation of L2 DA}

This section looks into a number of emergent themes focusing on the major conclusions and findings drawn from primary research on DA that can have implications for L2 teaching.

\section{General Benefits of DA}

The implementation of DA principles in daily interactions that teachers/mediators have with learners not only illuminates their level of development in terms of ZPD and focuses on the process of learners' performance rather than its product, but also affects their subsequent performance by developing their language abilities and helping them gain increasing control over certain features of language, become more independent, and perform autonomously (Lantolf \& Poehner, 2010). Vygotsky (1978) defined individuals' ZPD as the difference between their unassisted and assisted performance, and maintained that individuals' future unassisted performance would desirably reach the level of their current assisted performance. Put another way, in Vygotsky's (1978) terms, as cited in Poehner (2012), learner development starts on the intermental plane constructed through mediation and leads to the emergence of learners' ability to perform intramentally, using the internalized forms of symbolic mediation to self-regulate. DA, hence, is interested in both the process and product of learning. Not only does DA assess abilities achieved in the past, but also it intervenes in learning and develops emergent abilities. Despite showing similar abilities in non-dynamic assessment, learners might have dissimilar ZPD's, that is, different evolving language abilities and distinctive potentials to develop.

In addition, informed by Shrestha and Coffin's (2012) study, as far as learners' perception of DA is concerned, regarding it as 'more relaxed', 'encouraging', and 'supportive', they are very positive about it. A student has maintained that DA is "a great way of learning because the guidance questions helped me to think about what I did and how I could improve" (Shrestha \& coffin, 2012, p. 67). It is also acknowledged that DA can simultaneously make learning an enjoyable experience and enhance learners' language development (ibid, p. 59).

\section{Interaction and Mediation in DA}

Interaction and mediation are of pivotal importance in determining the accuracy of classroom assessment. In fact, DA has the potential to enhance and extend traditional models of assessment (Shrestha \& Coffin, 2012, p. 59). For instance, van Compernolle and Zhang (2014) argued that assistance provided during elicited imitation test of L2 English morphology uncovers and enhances the continued growth of emerging L2 abilities. As far as the approach taken to DA is concerned, interactionist approaches, that are dialogic and open-ended, compared to interventionist ones, in which scripted intervention is offered, are found to be more useful in classroom setting (Lantolf \& Poehner, 2004, p. 68). As discourse unfolds throughout mediation, the mediator is able to gain a better understanding of learners' capabilities. With regard to achievement tests, it should be noted that task difficulty and personal circumstances could affect learners' performance and enlarge error score accordingly. Hence, fulfilling diagnostic purposes, interaction and mediation have benefits for the pursuit of accurate assessment and designing individualized plans of development informed by learners' needs (Anton, 2009). Moreover, assessment without mediation overlooks the importance of future by merely evaluating performance at the end or the beginning of a curriculum (Lantolf \& Poehner, 2004; Poehner \& Lantolf, 2005). Meditational moves, targeted at learners' ZPD and made by the tutor, help diagnose the problem areas faced by learners and present an opportunity for learners to improve their skills and develop their conceptual knowledge.

Assistance offered by mediators must not be haphazard, but rather tailored, dynamic, and ongoing guidance finely tuned to learners' emerging needs and responsiveness to previous mediation as they move through their ZPDs is to be provided. Results of Nassaji and Swain's (2000) study on the effect of random versus negotiated help on the learning of English articles revealed that assistance provided within a learner's ZPD is more effective than help provided randomly. It is worth noting that learners value formative feedback and mediation as long as they are relevant and usable (Shrestha \& Coffin, 2012, p. 59).

\section{B. Guidelines on the Implementation of L2 DA}

Informed by an interpretation of DA primary research findings, this section provides a set of guidelines on the implementation of DA in classroom context and putative typologies of mediational strategies that can be adopted and/or adapted by teacher trainers and teachers in the pedagogical practice of their profession with regard to the nuances of the instructional context as well as the very language skill/component they deal with. A point which has to be carefully considered is that what is briefly presented in this section typifies axiom procedures, clines of mediational moves, and veritable cornerstones of DA which, doubtless, allow for variation in implementation beyond the skills they have been 
initially used for. They can serve as a blueprint for taking initial measures to commence the implementation of DA until teachers get principles of DA right and master them. Teachers' judicious choice and use of the guidelines is, indeed, a substantive matter with regard to fine-tuning and translating the presented principles into practice with the intent of producing optimal learning benefits and development.

\section{Making Use of Different Interactional Frames in Mediation}

Underscoring that ZPD, as a transformative activity, dialectally fuses assessment and teaching, Poehner and van Compernolle (2011) identified the following interactional frames, which can be jointly co-constructed with learners through mediation: (a) eliciting learner verbalization, which enables the mediator to determine a learner's understanding and problems; (b) collaborative interactional frame, in which the mediator targets support to learner needs and tracks this throughout the process of completing the task; and (c) cooperative interactional frame, entailing co-constructing and re-specifying a goal through interaction which is not necessarily central to the immediate task, but rather promotes learner knowledge; this can be done by addressing learners' problems or questions and can be initiated by either the mediator or a learner.

\section{Devising Mediation Inventories}

Informed by Lantolf and Poehner's (2010) study, following an interventionist approach to DA, teachers can prepare and use a mediation inventory for their prompts during mediation, as shown in Figure 1, in which the moves are sorted from most implicit (no. 1) to most explicit (no. 8). Doing so, teachers can assign numerical value to each mediating prompt. For example, a learner who requires level 2 mediation, will receive 2.

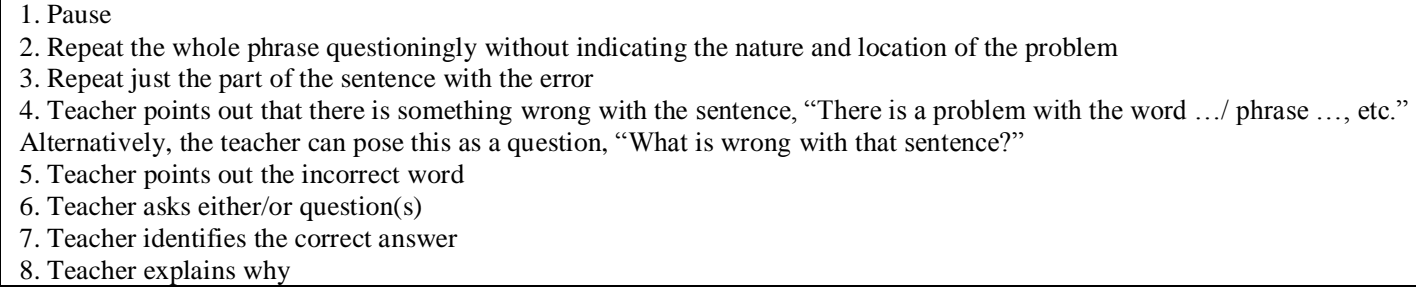

\section{Providing Mediational Moves}

Implementing DA, teachers are advised not to identify the error explicitly, nor should they provide learners with the correct answer. Instead, they must give room for self-correction, ask questions, request for verification/clarification, make reference to a previous problem, provide learners with alternate clues/prompts/forms/hints/suggestions, and make use of a detailed, graphic representation of the problematic area and/or concrete materials (e.g., cuisenaire rods). Mediators are to commence the mediation offering implicit assistance (e.g., eliciting an explanation of a certain response) and if learners are not able to spot and correct their errors, they must continue assisting them with their ZPD by resorting to more explicit mediational moves, which may reveal the nature of the problem (e.g., compare 'Can you explain that again?' with 'Let's start using present perfect tense.'). In concurrent G-DA the teacher must run through the whole array of mediating options with a single learner before moving to the next learner. However, because interactions shift between primary and secondary interactants, they must remain relevant.

Mediation cannot be offered in a haphazard manner no matter how it is offered, but rather must be gradual, contingent (Aljaafreh \& Lantolf, 1994), and "tuned to those abilities that are maturing, and as they mature further as a consequence of mediation, the mediation itself must be continually renegotiated" (Poehner \& Lantolf, 2005, p. 260). Put another way, meditational moves must be systematic, that is, attuned to learners' needs and abilities, graded in terms of explicitness, and consistent.

For instance, to figure out students' actual ability in a given area, teachers/mediators can ask information, yes/no, leading, and/or issue questions and use learners' response as a starting point for moving towards a more accurate analysis of the problem and continue until they find the main source of the problem. Some sample questions that can be asked include: Is there anything wrong here in this sentence? / Do you see anything wrong? / What's the right form? / So, you would say? / Do you remember? Is it ... (e.g., irregular, uncountable, etc.). Providing the answer and explaining why must be used as a last resort. Teachers can also start the task and hold learners responsible for finishing it, either individually or in a group with peers. Figure 2 provides a prime example of tutor mediational moves. 


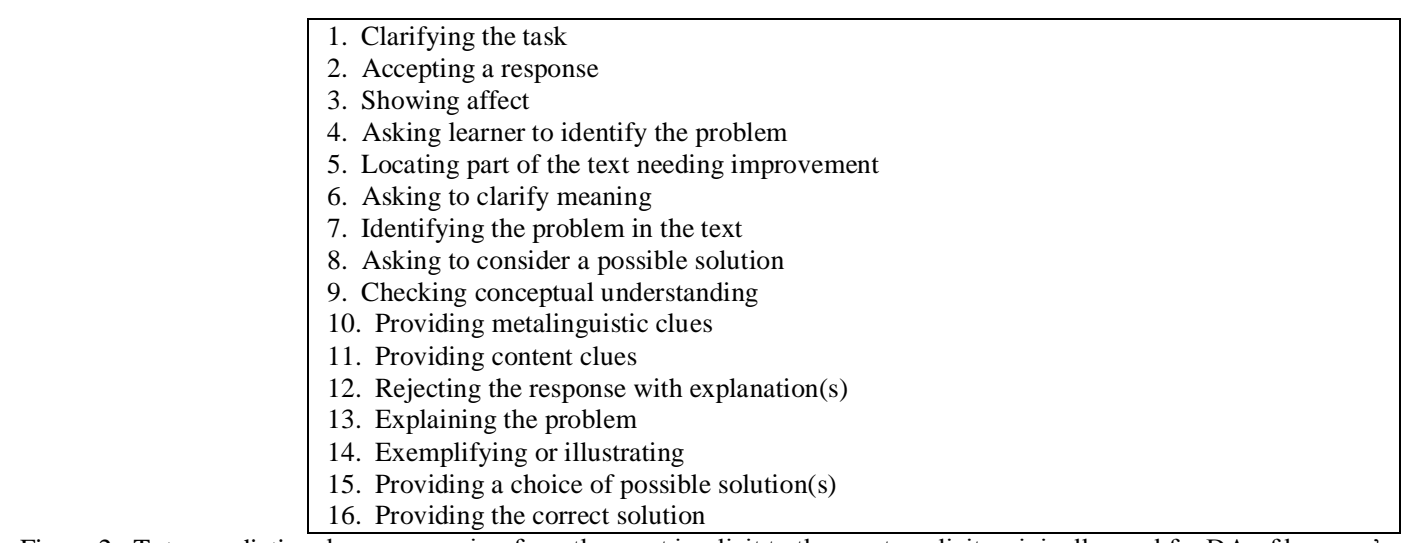

Figure 2. Tutor mediational moves ranging from the most implicit to the most explicit, originally used for DA of learners' writing ability (Shrestha \& Coffin, 2012, p. 61).

\section{Typology of Mediation Strategies}

\subsection{DA of Listening}

Ableeva (2010) addressed the individualized DA of L2 learners' listening abilities and devised a regulatory scale including a typology of meditational strategies as a posteriori, after analyzing the mediator's interactions with learners (see Figure 3).

$\mid$\begin{tabular}{ll|} 
1. & Accepting response \\
2. & Structuring the text \\
3. & Replay of a passage \\
4. & Asking the words \\
5. & Identifying a problem area \\
6. & Metalinguistic clues \\
7. & Offering a choice \\
8. & Translation \\
9. & Providing a correct pattern \\
10. Providing an explicit explanation
\end{tabular}
Figure 3. Mediation strategies, addressing the DA of learners' listening abilities (Ableeva, 2010, p. 260).

Two main goals can be pursued by going through the meditational stages: first, the problem areas that hamper comprehension can be identified, and, second, learners can be assisted with their language development.

Alavi et al. (2012) developed an inventory of meditational strategies, which can be used by language teachers during interactions with a group ZPD to track and enhance learners' development in listening comprehension (see Figure 4).

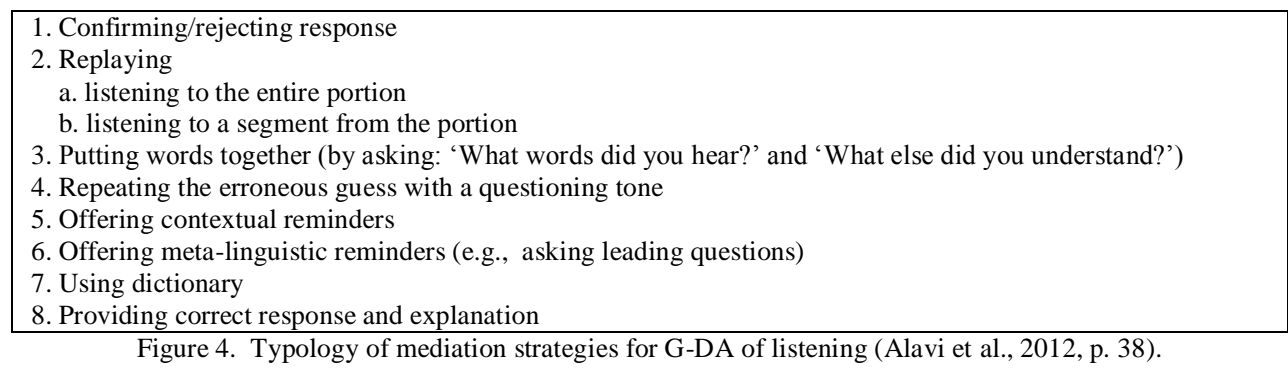

The strategies are ranged from the most abstract to the most concrete (no. 1-8). It is worth mentioning that 'listening to a segment from the portion' serves a diagnostic function by narrowing down the scope of the problem. The third strategy allows for co-construction of knowledge among learners, and the fourth one provides learners with the hint that their recall is incorrect. Contextual reminders, which can promote comprehension, include world schemata, topical knowledge, and situational awareness (i.e., information about discoursal features, participants, setting, and goal of language use). Meta-linguistic reminders, which draw students' attention to the adjacent words and co-text and aid developing an inference about a piece of utterance/text, range from various lexical cues to different grammatical hints (e.g., collocations, phrasal verbs, parts of speech, etc.). According to the devised inventory of meditational strategies, if learners are able to process a word phonologically but not semantically, they should be advised to consult their dictionaries to identify familiar but unrecognized lexical items among a number of hypothetical options and/or look up the meaning of new words. However, if learners are not even able to decode the aural form of a word, performing the instructional function (see section 4.4. of the present work) of G-DA, the mediator can explain the correct answer to help learners move up to a higher level of ZPD (Alavi et al., 2012).

\subsection{DA of Reading and Word Recognition}


Looking into the DA of word recognition and reading comprehension, Carney and Cioffi (1990) identified four modes of instructional episodes ranging from least to most intrusive: first, learners can be given independent easy silent reading tasks to report on. Second, learners can be given instruction on specific comprehension skills (e.g., figuring out the main idea/specific details). Third, general instructional support (e.g., activating schemata, preteaching low frequency words, etc.) can be offered. Fourth, learners can receive instruction on the use of metacognitive strategies (e.g., having control over reading, visualizing, thinking about the way (s) of processing information).

Carney and Cioffi (1990) argue that DA of word cognition and reading comprehension must be done through different instructional episodes, informed by learners' responsiveness to previous instruction, until the they either give the correct response or are proven unable to identify it (see also Table 1).

TABLE 1

FRAMEWORK FOR DYNAMIC ASSESSMENT (CARNEY \& CIOFFI, 1990, PP. 188-189)

Assessment Content (Rapid and Correct Identification)

1. Word Recognition in Isolation (Rapid and Correct Identification)

2. Word Recognition in Context (Unrehearsed Fluent Reading)

3. Comprehension - Oral and Silent Reading

(Correct Response to Comprehension Questions)

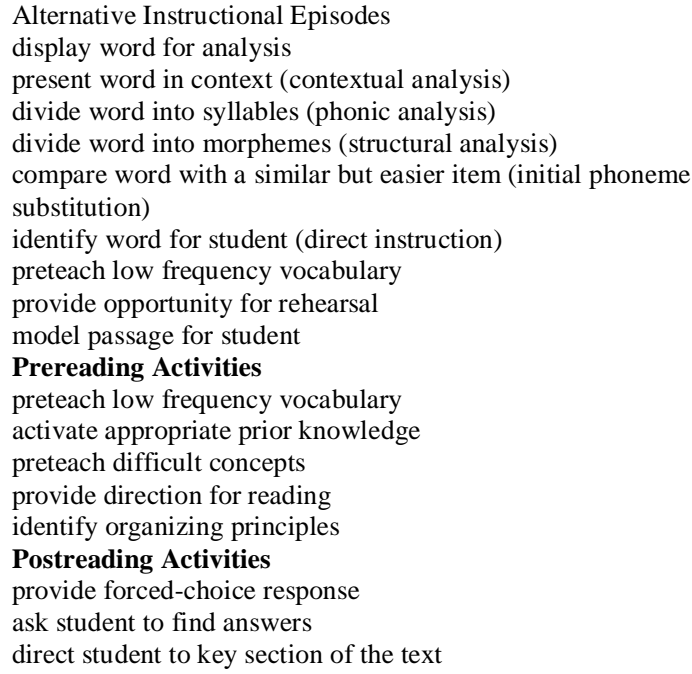

As shown in Table 1, conceiving of DA as a response-to-instruction paradigm, a number of DA procedures that mediators can use to help learners achieve success in word recognition and reading comprehension have been summarized. For full details of the implementation of each instructional episode, the explanation of which is beyond the scope of the present meta-synthesis, refer to Carney and Cioffi (1990).

\subsection{DA of Writing and Speaking}

Figure 5 presents a mediation typology for mediating learners' speaking ability. For a sample of tutor mediational moves while dealing with learners' writing sample, see Figure 2.

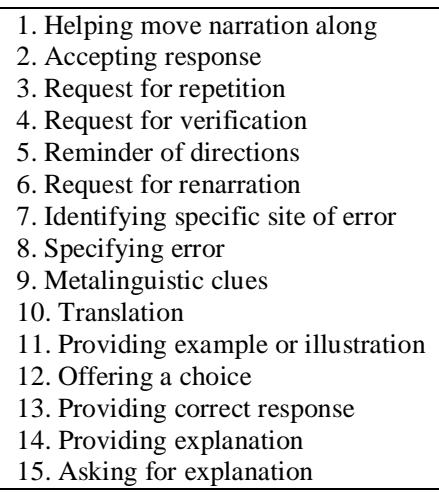

Figure 5. Tutor mediation typology, originally used for DA of learners' speaking ability (Poehner, 2005, p. 160).

\subsection{DA of Grammatical Competence}

Van Compernolle and Zhang (2014) provided a description of the procedures for offering gradual (i.e., from implicit to explicit) support to L2 learners taking an elicited imitation test of grammatical competence (see Table 2). More targeted, direct assistance was given as learners failed to respond to questions correctly. In the context of the abovementioned study, the test items were presented using audio-recordings; that is why the mediator was expected to 'play' the statements and ask a learner to 'listen' to them once more. Doubtless, the procedures can be modified to be maximally compliant with the demands of the targeted skill(s) in mediation. 
TABLE 2

OUTLINE OF INTERVENTIONIST DA PROCEDURES (VAN COMPERNOLLE \& ZHANG, 2014)

Step Procedure

1 Let student respond without assistance (independent performance).

If attempt 1 is not correct, prompt with: "Sorry, that wasn't quite right. Listen to the statement one more time and try to ..."; Provide a second chance to repeat the statement.

3 If attempt 2 is not correct, prompt with: "Sorry, that wasn't quite right either. Listen to the statement again and pay attention to ..."; 2 Narrow the focus to a specific unit of analysis.

4 If attempt 3 is not correct, prompt with: "Sorry, that still wasn't quite right. Listen to the statement again and think about ... (e.g., the plural form of .../ending of the verb .../past tense form of the verb ....”; Provide a metalinguistic prompt.

5 No more attempts. Provide the correct form and an explanation of the problem, and play the statement again.

Davin (2013) provided an insight into the way language teachers can carry out cumulative, interventionist DA. As shown in Table 3, whenever a student produced an incorrect utterance, the teacher can utilize a menu of hierarchical, pre-scripted prompts and gave the student an opportunity to correct the error/mistake. The teacher can also maintain a daily mediation record in which he/she systematically tracks the progress of each student (i.e., the number of mediation prompts required by and the source of the student's error).

TABLE 3

MEDiATION PROMPTS ORIGINALly USED FOR CUMULATIVE INTERVENTIONIST DA OF WH-QUESTION FORMATION (DAVIN, 2013, P. 310 ) Level of Explicitness Mediation Prompt

Prompt $1 \quad$ Pause with questioning look

Prompt $2 \quad$ Repetition of entire phrase by teacher with emphasis on source of error

Prompt 3 Repetition of specific site of error

Prompt $4 \quad$ Forced choice option

Prompt 5 Correct response and explanation provided

As can be seen, the graduated prompts become more and more explicit until the student can formulate the response correctly.

\section{CONCLUSIONS AND Discussion}

Teachers, unfortunately, barely consider the implications of DA for classroom teaching and learning (Lidz, 2009), and the blame partly lies with DA researchers and proponents, for they may have not enunciated the relevance and conformity of DA research findings to classroom context, or they may have been inadvertently neglectful of the need for clearly recounting how teachers can embark on administering DA in practice. It seems prudent to believe that the implementation of DA practices in pedagogical practices will be hampered unless their rich understandings and interpretations, gleaned from individual research reports, are synthesized and a framework to enhance the applicability of findings of primary studies are developed. That is, relevant empirical research findings still need to overcome instructional obstacles to gain practicality.

The present meta-synthesis drew the conclusion that findings and results of scholarly articles are, at least at times, couched in academic jargon, which is not easy for teachers or teacher educators to follow. Moreover, some research articles are hard to come by due to certain constraints on their accessibility and if available, collecting relevant research reports on DA, going through them all, and scrutinizing them is rather time-consuming. All these reasons, which can dissuade practitioners from obliging themselves to abide by recent developments in the field, that may seem to be surplus to requirements, call a halt to the incorporation of DA into teachers' pedagogical practice and draw DA into an esoteric world.

Problems with the investment of resources and time in compiling updated resources remain a barrier to DA being practiced as a part of teachers' professional practice. In the hope of breaking new ground for the incorporation of DA into the mainstream of classroom assessment and instructional practices, the present work was an attempt to systematically identify the empirical evidence of the effectiveness of DA on language learning in the previously conducted research, integrate their findings and implications to obtain a broader understanding of the applicability and practicality of DA practices, and avail teacher trainers and pre- and in-service teachers with an abridged account of the benefits and guidelines of DA; implementing them can be a departure point to bridge the gap between research and professional practice.

Informed by the findings of the present meta-synthesis, recommendations pertaining to practice, education, and research can be made. As Kozulin (2009) notes, classroom context is a promising vein for the implementation of DA because, at the time being, providing a large number of examinees with meditational means in formal testing is not feasible. However, it seems that classroom-based DA has yet to break into mainstream educational practice, and instructing pre- and in-service teachers to apply the principles of DA in their classroom (e.g., holding instructional workshops and seminars) can be a starting point for implementing DA. It is hoped that putting Vygostsky's proposal into practice will illuminate the nature and developmental processes of human cognition. 
Language teachers should bear in mind that for teaching to be effective, not only should links between assessment and classroom practice be made (Lidz, 1991), but also results of each stage of assessment must feed into their subsequent interventional moves. This cannot be achieved unless teacher educators and language teachers gain a clear understanding of DA, its principles, and practical application guidelines. Mediators/Teachers must monitor learners' ability to transfer principles of target constructs beyond a here-an-now given task, which heralds microgenesis, to more difficult transfer tasks.

As far as education is concerned, it is worth mentioning that whether and how DA can find its way to classroom context depends on the amount of political advocacy and educational empowerment it receives from stakeholders and policymakers. Moreover, teacher trainers/educators, who have a thorough grasp of DA and are willing to refurbish the entrenched views on classroom assessment, are to fittingly familiarize TTC attendees with the underlying assumptions of DA and some guidelines on how they can apply the principles to their own instructional practice by employing mediation with the aim of engaging in learners' ZPD, fostering learner development, and moving beyond questionresponse-feedback classroom discourse. Materials developers and syllabus designers are to be sensitized to the beneficial effects of DA in learner development and leave room for DA practices in the pedagogical materials (e.g., course books \& teacher guides) they develop.

A key limitation of this meta-synthesis is that although meta-synthesis studies have a mechanism for identifying main areas of focus in a given line of research through the inclusion and integration of multiple studies, the interpretive findings of existing research on the effectiveness of DA in classroom context is by no means limited to those included in the research. Given the purpose and scope of the present work, those studies on DA which focused on early childhood education, language therapy, language impairments, speech disorders, learning difficulties/disabilities, intellectual disabilities, computer-mediated DA, computerized DA (C-DA), DA of discourse abilities, and DA of syntactic organization were excluded; nevertheless, the inclusion of such research could have made further data available. The inevitable over-representation of articles written by a number of leading figures in the field and the exclusion of publications other than peer-reviewed articles are among other limitations of the present work.

Considering possibilities for employing various pedagogical means (e.g., portfolios, journals, etc.) that may encourage collaborative interaction throughout DA sessions in a variety of educational contexts (e.g., computerized and internet-based DA, classroom assessment practices, tutoring sessions, etc.) can give venue for new research projects. Given that parents are expected to be informed about their children's learning status/progress, implementing classroom DA might pose a challenge to the ease of communication between teachers and parents. Further research can help sort this problem out by devising a means of systematic report for DA. Future studies can also pursue avenues for considering the transcendence of DA sessions rather than their effects on learners' microgenetic development. Last but not least, the present meta-synthesis suggests a need to further explore the effect of task difficulty on transcendence mediation and how certain tasks (e.g., cooperative learning tasks) and classroom culture may be relevant to promoting classroom-based L2 DA.

\section{REFERENCES}

[1] Ableeva, R. (2010). Dynamic Assessment of listening comprehension in L2 French (Unpublished doctoral dissertation). Pennsylvania State University.

[2] Ableeva, R., \& Lantolf, J. (2011). Mediated dialogue and the microgenesis of second language listening comprehension. Assessment in Education: Principles, Policy \& Practice, 18(2), 133-149.

[3] Alavi, S. M., Kaivanpanah, S., \& Shabani, K. (2012). Group dynamic assessment: An inventory of mediational strategies for teaching listening. The Journal of Teaching Language Skills, 3(4), 27-58.

[4] Aljaafreh, A., \& Lantolf, J. P. (1994). Negative feedback as regulation and second language learning in the zone of proximal development. The Modern Language Journal, 78, 465-483.

[5] Allal, L., \& Pelgrims Ducrey, G. (2000). Assessment of-or in-the zone of proximal development. Learning and Instruction, $10,137-152$.

[6] Anton, M. (2009). Dynamic assessment of advanced second language learners. Foreign Language Annals, 42(3), 576-598.

[7] Blachowicz, C. L. Z. (1999). Vocabulary in dynamic reading assessment: Two case studies. Journal of Reading Psychology, 20, 213-236.

[8] Carney, J. J., \& Cioffi, G. (1990). Extending traditional diagnosis: The dynamic assessment of reading abilities. Reading Psychology, 11(3), 177-192. doi: 10.1080/0270271900110302

[9] Davin, K. J. (2013). Integration of dynamic assessment and instructional conversations to promote development and improve assessment in the language classroom. Language Teaching Research, 17(3) 303-322.

[10] Davin, K. J., \& Donato, R. (2013). Student collaboration and teacher-directed classroom dynamic assessment: A complementary pairing. Foreign Language Annals, 46(1), 5-22.

[11] Dorfler, T., Golke, S., \& Artelt, C. (2009). Dynamic assessment and its potential for the assessment of reading competence. Studies in Educational Evaluation, 35, 77-82.

[12] Ellis, R. (2010). Second language acquisition, teacher education and language pedagogy. Language Teaching 43(2), $182-201$.

[13] Ellis, R. (2013). Corrective feedback in teacher guides and SLA. Iranian Journal of Language Teaching Research 1(3), 1-18.

[14] Feuerstein, R., Falik, L., Rand, Y., \& Feuerstein, R. S. (2003). Dynamic assessment of cognitive modifiability. Jerusalem: ICELP Press.

[15] Gagné, N., \& Parks, S. (2013). Cooperative learning tasks in a Grade 6 intensive ESL class: Role of scaffolding. Language Teaching Research, 17(2), 188-209. 
[16] Gass, S. (1995). Learning and teaching: The necessary intersection. In F. Eckamn, D. Highland, P. Lee, J. Mileham, \& R. Weber (Eds.). Second Language Acquisition Theory and Pedagogy (pp. 3-20). New Jersey: Lawrence Erlbaum.

[17] Guk, I., \& Kellogg, D. (2007). The ZPD and whole class teaching: Teacher-led and student-led interactional mediation of tasks. Language Teaching Research, 11(3), 281-299.

[18] Hill, K., \& Sabet, M. (2009). Dynamic speaking assessment. TESOL Quarterly, 43(3), 537-545.

[19] Ishihara, N. (2010). Instructional Pragmatics: Bridging Teaching, Research, and Teacher Education. Language and Linguistics Compass, 4(10), 938-953. doi: 10.1111/j.1749-818x.2010.00242.x

[20] Kaniel, S. (2010). Domain specific vs domain general: Implications for dynamic assessment. Gifted Education International, 26, 95-109.

[21] Kozulin, A. (2003). Psychological tools and mediated learning. In A. Kozulin, B. Gindis, V. S. Ageyev, \& S. M. Miller (Eds.), Vygotsky's educational theory in cultural contexts (pp. 15-38). Cambridge: Cambridge University Press.

[22] Kozulin, A. (2009). New reference points for Dynamic Assessment (DA): A commentary on Karpov and Tzuriel. Journal of Cognitive Education and Psychology, 8(3), 242-245.

[23] Kozulin, A., \& Garb, E. (2002). Dynamic assessment of EFL text comprehension. School Psychology International, 23, 112127.

[24] Laing, S. P., \& Kamhi, A. (2003). Alternative assessment of language and literacy in culturally and linguistically diverse populations. Language, Speech, and Hearing Services in Schools, 34, 44-55.

[25] Lantolf, J. P. (2006). Language emergence: Implications for applied linguistics-A sociocultural perspective. Applied Linguistics, 27(4), 717-728.

[26] Lantolf, J. P. (2009). Dynamic assessment: The dialectic integration of instruction and assessment. Language Teaching, 42(3), 355-368. doi:10.1017/S0261444808005569

[27] Lantolf, J. P., \& Poehner, M. E. (2004). Dynamic assessment of L2 development: Bringing the past into the future. Journal of Applied Linguistics, 1, 49-72.

[28] Lantolf, J. P., \& Poehner, M. E. (2010). Dynamic assessment in the classroom: Vygotskian praxis for second language development. Language Teaching Research, 15(1), 11-33.

[29] Lantolf, J. P., \& Poehner, M. E. (2013). The unfairness of equal treatment: Objectivity in L2 testing and dynamic assessment. Educational Research and Evaluation, 19(2-3), 141-157. doi: 10.1080/13803611.2013.767616

[30] Leung, C. (2007). Dynamic assessment: Assessment for and as teaching? Language Assessment Quarterly, 4(3), $257-278$. doi:10.1080/15434300701481127

[31] Lidz, C. S. (1991). Practitioner's guide to dynamic assessment. New York: Guilford Press.

[32] Lidz, C. S. (2009). Dynamic assessment, progress, problems, and prospects: A commentary on Karpov and Tzuriel. Journal of Cognitive Education and Psychology, 8(3), 238-41.

[33] Major, C. H., \& Savin-Baden, M. (2010). An introduction to qualitative research synthesis: Managing the information explosion in social science research. New York: Routledge.

[34] Murphy, R., \& Maree, D. J. F. (2006). Meta-analysis of dynamic assessment research in South Africa. Journal of Cognitive Education and Psychology [online], 6(1), 32-60.

[35] Nassaji, H., \& Swain, M. (2000). A Vygotskian perspective on corrective feedback in L2: The effect of random versus negotiated help on the learning of English articles. Language Awareness, 9(1), 34-51.

[36] Noblit G., \& Hare, R. (1988). Meta-Ethnography: Synthesising Qualitative Studies. Newbury Park: Sage.

[37] Norris, J. M., \& Ortega, L. (2007). The future of research synthesis in applied linguistics: Beyond art or science. TESOL Quarterly, 41(4), 805-815.

[38] Nuland, S. V. (2011). Teacher education in Canada. Journal of Education for Teaching, 37(4), 409-421.

[39] Nunan, D. (1991). Language teaching methodology: A textbook for teachers. London: Prentice Hall.

[40] Orwin, R. (1994). Evaluating coding decisions. In H. Cooper \& L. Hedges (Eds.), The handbook of research synthesis (pp. 139162). New York: Russell Sage Foundation.

[41] Poehner, M. E. (2005). Dynamic assessment of advanced L2 learners of French (Doctoral dissertation, Pennsylvania State University). Retrieved from https://etda.libraries.psu.edu/paper/6627/1890_(accessed 14/7/2014).

[42] Poehner, M. E. (2007). Beyond the test: L2 dynamic assessment and the transcendence of mediated learning. The Modern Language Journal, 91(3), 323-340.

[43] Poehner, M. E. (2008). Dynamic assessment: A Vygotskian approach to understanding and promoting L2 development. New York: Springer.

[44] Poehner, M. E. (2009a). Dynamic assessment as a dialectical framework for classroom activity: Evidence from second language (L2) learners. Journal of Cognitive Education and Psychology, 8(3), 252-268.

[45] Poehner, M. E. (2009b). Group dynamic assessment: Mediation for the L2 classroom. TESOL Quarterly, 43(3), $471-791$.

[46] Poehner, M. E. (2011a). Dynamic Assessment: Fairness through the prism of mediation. Assessment in Education: Principles, Policy \& Practice, 18(2), 99-112.

[47] Poehner, M. E. (2011b). Validity and interaction in the ZPD: Interpreting learner development through L2 Dynamic Assessment. International Journal of Applied Linguistics, 21(2), 244-263.

[48] Poehner, M. E. (2012). The zone of proximal development and the genesis of self-assessment. The Modern Language Journal, 96(4), 610-622. doi: 10.1111/j.1540-4781.2012.01393.x

[49] Poehner, M. E., \& Lantolf, J. P. (2005). Dynamic assessment in the language classroom. Language Teaching Research, 9(3), 233-265.

[50] Poehner, M. E., \& Lantolf, J. P. (2010). Vygotsky's teaching-assessment dialectic and L2 education: The case for dynamic assessment. Mind, Culture, and Activity, 17, 312-330.

[51] Poehner, M. E., \& Lantolf, J. P. (2013). Bringing the ZPD into the equation: Capturing L2 development during Computerized Dynamic Assessment (C-DA). Language Teaching Research, 17(3), 323-342. 
[52] Poehner, M. E., \& van Compernolle, R., A. (2011). Frames of interaction in Dynamic Assessment: Developmental diagnoses of second language learning. Assessment in Education: Principles, Policy \& Practice, 18(2), 183-198.

[53] Rea-Dickins, P. (2004). Understanding teachers as agents of assessment. Language Testing, 21, 249-258.

[54] Rezaee, A. A., \& Ghanbarpour, M. (2016). The measurement paradigm and role of mediators in dynamic assessment: A qualitative meta-synthesis. International Journal of Language Studies, 10 (4), 77-108.

[55] Sandelowski, M., Docherty, S., \& Emden, C. (1997). Qualitative metasynthesis: Issues and techniques. Research in Nursing and Health, 20, 365-371.

[56] Shrestha, P., \& Coffin, C. (2012). Dynamic assessment, tutor mediation and academic writing development. Assessing Writing, $17,55-70$

[57] Suri, H., \& Clarke, D. (2009). Advancements in research synthesis methods: From a methodologically inclusive perspective. Review of Educational Research, 79, 395-430.

[58] *Swanson, H. L., \& Lussier, C. M. (2001). A selective synthesis of the experimental literature on Dynamic Assessment. Review of Educational Research, 71(2), 321-363.

[59] Tellez, K., \& Waxman, H. C. (2006). A meta-synthesis of qualitative research on effective teaching practices for English Language Learners. In J. M. Norris \& L. Ortega (Eds.), Synthesizing research on language learning and teaching (pp. 245-277). Amsterdam, The Netherlands: John Benjamins B.V.

[60] Thorne, S. E., Jensen, L., Kearney, M. H., Noblit, G. W., \& Sandelowski, M. (2004). Qualitative metasynthesis: Reflections on methodological orientation and ideological agenda. Qualitative Health Research, 14, 1342-1365.

[61] Tierney, R. D. (2006). Changing practices: Influences on classroom assessment. Assessment in Education, 13(3), $239-264$.

[62] van Compernolle, R. A., \& Kinginger, C. (2013). Promoting metapragmatic development through assessment in the zone of proximal development. Language Teaching Research, 17(3) 282-302.

[63] van Compernolle, R. A., \& Williams, L. (2012). Promoting sociolinguistic competence in the classroom zone of proximal development. Language Teaching Research, 16(1), 39-60.

[64] van Compernolle, R. A., \& Williams, L. (2013). Sociocultural theory and second language pedagogy. Language Teaching Research, 17(3), 277-281.

[65] van Compernolle, R. A., \& Zhang, H. (S.). (2014). Dynamic assessment of elicited imitation: A case analysis of an advanced L2 English speaker. Language Testing, 31(4), 395-412.

[66] Vygotsky, L. S. (1978). Mind in society: The development of higher psychological processes. Cambridge, MA: Harvard University Press. (Original work published in 1955).

[67] Welch, S. K. (2008). A metasynthesis of the transition from novice to expert: Can instructional interventions shorten the process? (Doctoral dissertation). Retrieved from ProQuest (accessed 21/7/2014). (ProQuest Document ID 304821165)

[68] Yeomans, J. (2008). Dynamic assessment practice: Some suggestions for ensuring follow up. Educational Psychology in Practice, 24(2), 105-114. doi: 10.1080/02667360802076107

[69] Zhao, S. (1991). Metatheory, metamethod, qualitative meta-analysis: What, why, and how? Sociological Perspectives, 34(3), 377-390.

Mahsa Ghanbarpour obtained her Ph.D. in TEFL from University of Tehran. She did her M.A. in TEFL at the same university. Her research interests are Dynamic Assessment, Formative Assessment, Teacher Education, and Learner characteristics in Second Language Acquisition. 